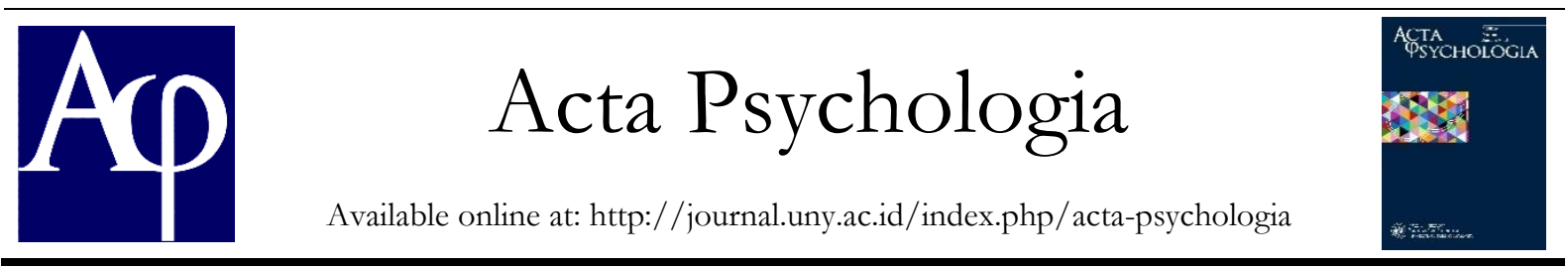

\title{
Hubungan antara Sense of Humor dengan Stres Kerja pada Pegawai
}

\author{
Muhammad Yoga Wiratama ${ }^{1}$, Rabmatika Kurnia Romadhani ${ }^{2}$ \\ ${ }^{1,2}$ Jurusan Psikologi, Fakultas Ilmu Pendidikan, Universitas Negeri Yogyakarta; Jl. Colombo No. 1 \\ Sleman Yogyakarta, 55281 \\ tyoga324@gmail.com
}

\begin{abstract}
Abstrak
Penelitian ini bertujuan untuk meneliti hubungan antara sense of humor dengan stres kerja pada pegawai. Dalam penelitian ini pendekatan yang digunakan adalah pendekatan kuantitatif dengan jenis penelitian korelasional. Subjek yang terlibat dalam penelitian ini adalah 41 pegawai PT. NN Yogyakarta. Instrumen pengumpulan data berupa skala sense of humor dan skala stres kerja. Skala sense of humor terdiri dari 22 item dengan reliabilitas sebesear 0,858 dan skala stres kerja terdiri dari 21 item dengan reliabilitas sebesar 0,916. Hasil analisis data menggunakan Pearson Product Moment menunjukkan bahwa terdapat hubungan antara sense of humor dengan stres kerja pada pegawai PT. NN dengan nilai korelasi sebesar -0,535 dan signifikansi $\mathrm{p}<0,05$ yang berarti semakin tinggi sense of humor maka semakin rendah stres kerja, begitu juga sebaliknya.
\end{abstract}

Kata Kunci: sense of humor, stres kerja, pegawai

\begin{abstract}
This study aims to determine the relationship between a sense of humor and work stress in employees. This study used a quantitative approach with correlational research type. The subjects were 41 employees from PT. NN Yogyakarta. The data collection instruments were a sense of humor scale and a work stress scale. The sense of humor scale consists of 22 items with a reliability of 0.858 and the work stress scale consists of 21 items with a reliability of 0.916 . Based on the results of data analysis using Pearson Product Moment, it shows that there is a relationship between a sense of humor and work stress on employees of PT. NN with a correlation value of 0.535 and a significance of $\mathrm{p}<0.05$, which means that the higher the sense of humor, the lower the work stress, and vice versa.
\end{abstract}

Keywords: sense of bumor, work stress, employees

\section{Pendahuluan}

Suatu organisasi atau perusahaan selalu mengharapkan hasil kerja yang maksimal dari seluruh pegawainya. Namun usaha tersebut tidak selamanya berjalan dengan baik. Hal ini dikarenakan banyak faktor yang mempengaruhi tingkah laku pegawai ketika bekerja. Salah satunya adalah stres kerja. Menurut Sormin (2016) masalah stres kerja merupakan ancaman yang serius bagi kesehatan pekerja dan dapat memberi ancaman serius bagi organisasi

Stres kerja dapat membawa akibat yang buruk. Griffin dan Moorhead (2013) menyebutkan bahwa stres kerja dapat berakibat secara perilaku, psikologi dan fisiologis. Secara fisiologis, stres kerja dapat menyebabkan beberapa masalah kesehatan. Sementara itu, secara psikologis stres kerja pada dasarnya dapat menyebabkan buruknya kesehatan mental yang dialami oleh individu seperti, kegelisahan, 
kebosanan, kelelahan, dan kehilangan kesabaran. Selain itu, secara perilaku stres kerja juga dapat menyebabkan perilaku yang kurang baik seperti sering absen, terlambat, mengkonsumsi alkohol, penyalahgunaan obat, dan kurangnya nafsu makan (Wartono \& Mochtar, 2015).

Berbagai macam kondisi kerja dapat menyebabkan pegawai mengalami stres. Lady dkk (2017) dalam hasil penelitiannya menyatakan bahwa penyebab stres kerja pada pegawai yaitu, penilaian diri, konflik peran, konflik interpersonal, kurangnya kontrol, kurangnya kesempatan kerja, dan jumlah beban kerja yang dilaksanakan pegawai terlalu berlebihan. Quick dkk (2017) berpendapat bahwa kelebihan beban kerja, tekanan waktu, dan perubahan tugas adalah salah satu sumber stres kerja terbesar bagi orang-orang di banyak pekerjaan dan organisasi.

Menurut survei Health and Safety Executive (HSE) pada tahun 2017/2018 sebanyak 595.000 orang di inggris melaporkan bahwa mereka merasakan stres terkait dengan pekerjaannya. Stres, depresi, atau kecemasan terkait dengan pekerjaan sudah mencapai kondisi yang sangat buruk di Inggris. Hal ini membuktikan bahwa stres terkait pekerjaan dianggap sebagai dampak buruk bagi kesehatan mental pekerja (Health and Safety Executive, 2018). Menurut Johnson, dkk (2005) hampir setiap pekerja di banyak organisasi pasti mengalami stres dalam bekerja.

Banyak yang beranggapan bahwa stres akan menimbulkan akibat-akibat yang negatif bagi perusahaan maupun organisasi. Efek negatif dari stres juga akan menimbulkan kerugian pada pegawai. Seperti misalnya kasus yang terjadi pada tanggal 8 Januari 2018, dimana publik dikejutkan oleh pemberitaan Karyawan BRI bunuh diri di tanah abang Jakarta Pusat. Karyawati tersebut mengakhiri hidupnya dengan cara menjatuhkan diri dari gedung area parkir lantai 10. Setelah diselidiki korban diduga nekat mengakhiri hidupnya lantaran stres akibat tekanan pekerjaannya atau diduga mengalami stres kerja (wartakota.tribunnews.com).

Stres harus diatasi dengan cara yang tepat, agar dapat mengurangi akibat negatif dari stres. Upaya untuk mengatasi stres pada individu bisa dikenal dengan istilah coping. Coping sendiri merupakan usaha untuk menetralisir atau mengurangi stres yang terjadi pada individu (Sarafino, dalam Maryam 2017). Mekanisme yang digunakan untuk melakukan coping juga bervariasi, salah satunya adalah coping stres menggunakan humor.

Menurut Fritz dkk (2017) penggunaan humor sebagai strategi coping antara lain dengan cara mengubah pandangan individu pada situasi yang penuh tekanan dengan melihat tantangan itu sebagai hal yang positif. Humor juga dapat menimbulkan interaksi sosial yang positif, dan menjauhkan diri dari emosi negatif sehingga fokus pada emosi positif yang dapat mengurangi stres.

Namun akhir-akhir ini humor dianggap sebagai ketidakseriusan dalam bekerja bagi pegawai. Banyak perusahaan maupun organisasi menganggap bercanda selama bekerja dapat menyebabkan kelalaian dalam bekerja pada pegawai (Munandar dkk, 2014). Padahal humor menggambarkan sifat yang terhubung secara luas terkait dengan komunikasi lucu yang menghasilkan emosi positif dalam individu, kelompok, dan organisasi (Romero \& Cruthirds, 2006), dan membuat para pegawai menunjukkan peningkatan performa bekerja. Oleh sebab itu, jika humor digunakan dengan baik maka humor memiliki manfaat bagi individu di tempat kerja. Menurut Morreall (1991) ada tiga manfaat humor yang ada di tempat kerja yaitu promosi kesehatan, fleksibilitas mental, dan hubungan sosial yang baik. 


\section{Metode Penelitian}

Jenis Penelitian

Penelitian ini menggunakan pendekatan kuantitatif karena data penelitiannya berupa angka-angka dan analisisnya menggunakan statistik (Sugiyono, 2017). Azwar (2018) menjelaskan bahwa pendekatan kuantitatif yaitu metode yang menekankan analisis pada data-data yang dikumpulkan melalui prosedur pengukuran dan diolah dengan metode analisis statistika.

Jenis penelitian ini menggunakan metode penelitian korelasional. Menurut Azwar (2018) tujuan dari penelitian korelasional ini adalah untuk mengetahui kekuatan dan arah hubungan yang ada di antara variabel-variabel.

\section{Waktu dan Tempat Penelitian}

Penelitian dilaksanakan di PT. NN Yogyakarta yang dilaksanakan pada bulan Agustus-September 2020.

\section{Populasi Penelitian}

Menurut Sugiyono (2017) populasi merupakan wilayah generalisasi yang terdiri atas obyek atau subyek yang mempunyai kualitas dan karakteristik tertentu yang ditetapkan peneliti untuk dipelajari dan kemudian ditarik kesimpulannya. Populasi dalam penelitian ini adalah pegawai PT NN yang berjumlah 50 pegawai.

Dari 50 orang subjek pegawai PT NN terdapat sembilan orang subjek yang hasilnya tidak dapat dipakai dikarenakan angket yang sudah diberikan masih dalam keadaan kosong. Dalam hal ini total seluruh subjek yang digunakan penelitian ini berjumlah 41 orang. Dengan demikian penelitian ini dapat dikategorikan sebagai penelitian populasi.

\section{Teknik dan Instrumen Pengumpulan Data}

Teknik pengumpulan data pada riset ini menggunakan metode kuesioner (angket). Instrumen yang digunakan untuk mengumpulkan data menggunakan skala psikologi. Ada 2 skala dalam penelitian ini yaitu: skala sense of bumor dan skala stres kerja. Skala sense of bumor diusulkan oleh Thorson \& Powell, yang telah dimodifikasi oleh Satria (2019). Sementara itu, skala stres kerja menggunakan skala yang sudah dibuat oleh Tambun (2018).

Skala penelitian terdiri dari empat bentuk alternatif jawaban, yaitu sangat sesuai (SS), sesuai (S), tidak sesuai (TS), dan sangat tidak sesuai (STS). Skala stres kerja memiliki jumlah item sebanyak 21 item valid dengan nilai reliabilitas 0,916 , sedangkan skala sense of bumor memiliki jumlah item yang valid sebanyak 22 dengan nilai reliabilitasnya 0,858 .

\section{Teknik Analisis Data}

Analisis data yang akan dilakukan adalah analisis deskriptif dan uji hipotesis dengan korelasi Product Moment Pearson. Menurut Azwar (2018) analisis deskriptif memiliki tujuan untuk memberikan deskripsi atau gambaran mengenai data dari variabel yang diperoleh dari kelompok subjek penelitian. Data yang telah diperoleh dari skala sense of humor dan skala stres kerja masih berupa data yang terdiri dari kategori sangat tidak sesuai (nilai satu), tidak sesuai (nilai dua), sesuai (nilai tiga), dan sangat sesuai (nilai empat).

Analisis yang digunakan untuk menguji hipotesis penelitian ini menggunakan korelasi Product Moment Pearson dengan bantuan SPSS for Windows. Uji hipotesis ini juga bertujuan untuk mencari arah hubungan yang bersifat positif atau negatif. Koefisien korelasi yang bertanda positif berarti hubungan linier yang terjadi di antara X dan Y merupakan hubungan searah, yaitu naiknya skor $\mathrm{X}$ diikuti oleh naiknya skor $\mathrm{Y}$ dan begitu juga sebaliknya. Sedangkan, koefisien bertanda negatif berarti hubungan yang terjadi antara X dan Y merupakan hubungan yang berlawanan arah, yaitu menurunnya skor $\mathrm{X}$ akan cenderung diikuti naiknya skor $Y$ dan begitu juga sebaliknya (Azwar, 2018). 


\section{Hasil Penelitian dan Pembahasan}

Deskripsi Data Kategorisasi Stres Kerja

Data stres kerja dikategorikan dengan menggunakan rerata empirik, standar deviasi empirik, rerata hipotetik, dan standar deviasi hipotetik. Rerata empirik yang diperoleh pada data stres kerja adalah 37,78 sedangkan standar deviasi empirik yang diperoleh yaitu 6,955. Selanjutnya rerata hipotetik pada data stres kerja adalah 52,5 sedangkan standar hipotetik yang diperoleh yaitu 10,5.

Tabel 1. Kategorisasi Stres Kerja

\begin{tabular}{llcc}
\hline Kategori & Interval Skor & $\begin{array}{c}\text { Fre- } \\
\text { kuensi }\end{array}$ & $\begin{array}{c}\text { Persen- } \\
\text { tase }\end{array}$ \\
\hline Sangat & $\mathrm{X}>69$ & 0 & $0 \%$ \\
Tinggi & & & \\
Tinggi & $58<\mathrm{X} \leq 68$ & 0 & $0 \%$ \\
Sedang & $48<\mathrm{X} \leq 57$ & 2 & $4,9 \%$ \\
Rendah & $38<\mathrm{X} \leq 47$ & 23 & $56,1 \%$ \\
Sangat & $\mathrm{X} \leq 37$ & 16 & $39 \%$ \\
Rendah & & & \\
& Total & 41 & $100 \%$ \\
\hline
\end{tabular}

Tabel 1 di atas dapat menunjukkan bahwa tingkat stres kerja pada PT NN terbagi dalam beberapa kategori yaitu kategori sedang sebesar 4,9\% (2 orang), kategori rendah sebesar $56,1 \%$ (23 orang), kategori sangat rendah sebesar 39\% (16 orang), dan pada kategori tinggi dan sangat tinggi tidak ditemukan pegawai yang termasuk dalam kategori tersebut.

Maka dapat disimpulkan bahwa sebagian besar subjek memiliki tingkat stres kerja pada kategori rendah, yaitu sebanyak 23 orang atau sekitar $56,1 \%$.

Data sense of bumor dikategorikan dengan menggunakan rerata empirik, standar deviasi empirik, rerata hipotetik, dan standar deviasi hipotetik. Rerata empirik yang diperoleh pada data stres kerja adalah 67,80 sedangkan standar deviasi empirik yang diperoleh yaitu 5,711. Selanjutnya rerata hipotetik pada data stres kerja adalah 55 sedangkan standar hipotetik yang diperoleh yaitu 11 .

Tabel 2. Kategorisasi Sense of Humor

\begin{tabular}{llcc}
\hline Kategori & Interval Skor & $\begin{array}{c}\text { Frekuensi } \\
\text { Persen- } \\
\text { tase }\end{array}$ \\
\hline $\begin{array}{llcc}\text { Sangat } \\
\text { Tinggi }\end{array}$ & $\mathrm{X}>73$ & 8 & $19,5 \%$ \\
Tinggi & $61<\mathrm{X} \leq 72$ & 32 & $78 \%$ \\
Sedang & $50<\mathrm{X} \leq 60$ & 1 & $2,4 \%$ \\
Rendah & $39<\mathrm{X} \leq 49$ & 0 & $0 \%$ \\
Sangat & $\mathrm{X} \leq 38$ & 0 & $0 \%$ \\
Rendah & & 41 & $100 \%$ \\
Total & & 4
\end{tabular}

Berdasarkan data dari tabel 2, diketahui tidak ada pegawai PT NN yang termasuk dalam kategori rendah dan sangat rendah. Kategori sedang pada kategorisasi sense of bumor terdapat 2,4\% (1 orang), kategori tinggi sebesar 78\% (32 orang), dan pada kategori sangat tinggi sebesar 19,5\% (8 orang). Maka dapat disimpulkan bahwa sebagian besar subjek memiliki tingkat sense of bumor pada kategori tinggi, yaitu sebanyak 32 orang atau sekitar $78 \%$.

\section{Uji Hipotesis}

Uji hipotesis dilakukan untuk mengetahui hubungan antara variabel sense of bumor dan stres kerja. Uji hipotesis dilakukan dengan menggunakan Korelasi Pearson Product Moment dengan bantuan SPSS for Windows.

Tabel 3. Hasil Korelasi Pearson Product Moment

\begin{tabular}{llcc}
\hline & Variabel & 1 & 2 \\
\hline 1 & Sense of humor & 1 & $-0,535^{* *}$ \\
2 & Stres kerja & $-0,535^{* *}$ & 1 \\
\hline${ }^{*}$ signifikean pada $p<0,01$ & &
\end{tabular}

Berdasarkan Tabel 3. dapat dilihat bahwa Korelasi Pearson Product Moment menunjukkan nilai koefisien korelasi sebesar $-0,535$ dengan nilai signifikansi sebesar $\mathrm{p}<0,01$. Hal ini menunjukkan bahwa variabel sense of bumor memiliki hubungan yang negatif terhadap variabel 
stres kerja pada pegawai PT NN. Artinya semakin tinggi sense of humor maka semakin rendah stres kerja pada pegawai dan begitu juga sebaliknya.

Berdasarkan tabel 1. hasil analisis deskriptif stres kerja menunjukkan bahawa pegawai PT. NN mayoritas memiliki tingkat stres kerja yang rendah yaitu sebanyak 58,5\%. Artinya pegawai yang ada di perusahaan mampu mengontrol atau mengelola stres menjadi lebih baik. Menurut Sukoco dan Bintang (2017) stres dalam pekerjaan dapat dicegah sehingga dapat dihadapi tanpa menimbulkan dampak negatif. Melakukan manajemen stres berarti berusaha mencegah timbulnya stres, meningkatkan ambang stres atau menampung akibat fisiologis dari stres. Hal ini menjadikan pegawai PT. NN memiliki tingkat stres kerja yang rendah karena mampu mengontrol penyebab stres kerja.

Berdasarkan tabel 2. hasil analisis deskriptif variabel sense of bumor menunjukkan bahwa pegawai PT. NN mayoritas memiliki tingkat sense of bumor yang tinggi. Artinya, individu yang memiliki kepekaan humor (sense of bumor) yang tinggi mampu mengubah persepsinya terhadap stresor yang diterimanya dengan memandang dari segi kelucuan sehingga tidak lagi menjadi situasi yang mengancam atau tidak menyenangkan (Widyowati \& Priambodo, 2016). Selain itu, sense of bumor yang tinggi dapat meningkatkan kepuasan kerja dari para pegawai (Daryansyah \& Duryati, 2015). Hal ini menunjukkan bahwa pegawai yang ada di perusahaan memiliki sense of bumor yang baik. Menurut Puspitacandri (2013) individu yang memiliki sense of humor yang baik akan lebih rileks dalam menghadapi masalah karena humor dapat mengurangi ketegangan yang diakibatkan oleh suatu masalah.

Di setting perusahaan maupun organisasi biasanya humor memiliki fungsi untuk mengurangi stres kerja. Seperti yang disebutkan Suyasa (2010:2) bahwa fungsi sense of bumor sebagai pelengkap dalam memimpin, sarana komunikasi, penghambat agresivitas, sarana dalam proses terapi dan untuk mengurangi stres pada individu.

Penelitian ini memiliki tujuan untuk mengetahui hubungan antara sense of bumor dengan stres kerja pada pegawai. Berdasarkan hasil uji hipotesis menggunakan korelasi Pearson product moment diketahui bahwa terdapat korelasi negatif yang cukup atau sedang antara sense of humor dengan stres kerja sebesar - 0,535 dengan signifikansi 0,000 . Artinya semakin tinggi sense of humor maka semakin rendah stres kerja pada pegawai dan begitu juga sebaliknya. Hasil penelitian ini sesuai dengan hipotesis yang telah ditentukan yaitu terdapat hubungan negatif antara sense of humor dengan stres kerja pada pegawai.

Hasil penelitian ini sejalan dengan penelitian Widyowati dan Priambodo (2016) dengan judul "Hubungan antara Kepekaan Humor dengan Stres Kerja pada Pegawai Balai Karantina Pertanian Kelas 1 Semarang Jawa Tengah". Subjek yang terlibat dari penelitian berjumlah 52 orang. Hasil dari penelitian ini menunjukkan semakin tinggi kepekaan humor yang dimiliki pegawai maka semakin rendah stres kerja pada pegawai.

Menurut Lippit (dalam Batool \& Zubair, 2014) ketika humor digunakan dengan cara yang positif akan membawa potensi untuk bertindak sebagai penunjang terhadap efek buruk dari stres di tempat kerja melalui penggunaannya sebagai strategi coping. Sense of bumor dalam penelitian yang dikemukakan Magnus, Glew, dan Viswesvaran (2012) menunjukkan bahwa efek positif dari humor di tempat kerja antara lain: dapat menimbulkan peningkatan kerja, menciptakan hubungan yang baik antar anggota, memberikan kesehatan, dan menurunkan kelelahan. Oleh karena itu, berdasarkan penelitian ini, sense of bumor 
dapat dimanfaatkan pegawai untuk mengatasi stres dalam bekerja.

\section{Simpulan dan Saran}

\section{Simpulan}

Berdasarkan penelitian di atas dapat disimpulkan bahwa sense of humor memiliki hubungan negatif yang signifikan dengan stres kerja. Artinya semakin tinggi sense of humor maka akan semakin rendah stres kerja. Sebaliknya, semakin rendah sense of bumor maka semakin tinggi stres kerja, sehingga hipotesis dalam penelitian ini diterima.

\section{Saran}

Berdasarkan kesimpulan dari penelitian yang sudah dilakukan, maka saran yang dapat diberikan yaitu sebagai berikut:

1. Bagi Perusahaan: Disarankan bagi PT.

NN agar dapat membuat programprogram mengenai cara menghadapi masalah stres kerja pada pegawai dengan memanfaatkan sense of bumor yang dimiliki oleh pegawai. Adapun program yang dapat dijalankan untuk memanfaatkan sense of bumor antara lain memberikan fasilitas hiburan seperti menonton film komedi di waktu istirahat agar pegawai tetap mempertahankan kemampuan sense of bumor dalam mengatasi masalah.

2. Bagi Pegawai : Pegawai PT. NN diharapkan mampu mempertahankan kemampuan sense of bumor yang tinggi dapat mengatasi masalah stres pada saat menghadapi situasi yang cenderung menekan di tempat kerja, sehingga dapat menciptakan suasana positif di tempat kerja. Pegawai PT. NN juga diharapkan mampu menggunakan sense of bumor secara baik sehingga dapat mengurangi efek negatif lingkungan kerja seperti konflik antar pegawai, menurunnya kinerja, dan beban kerja yang berlebihan. Pegawai juga disarankan untuk selalu menyisipkan humor sebagai bentuk komunikasi lucu agar dapat menciptakan suasana yang positif di lingkungan kerja.

Penelitian selanjutnya : Bagi peneliti selanjutnya, disarankan untuk mencari lebih banyak kajian teori mengenai coping melalui humor dalam mengatasi stres kerja serta melakukan riset mengenai tingkat atau level dari sense of humor dan stres kerja ditinjau dari aspek lain. Peneliti selanjutnya juga diharapkan melakukan upaya untuk mengambil subjek yang lebih banyak dan dapat memperbaiki kekurangan penelitian ini guna memperkuat hasil pembahasan mengenai hubungan sense of bumor dengan stres kerja.

\section{Daftar Pustaka}

Azwar, S. (2018). Metode penelitian psikologi (2 ed.). Yogyakarta: Pustaka Pelajar.

Baskoro, R. (2018, Januari 1). Diduga stres bekerja, karyawati BRI bunuh diri. Retrieved from wartakota.tribunnews.com

Batool, S., \& Syeda, Z. (2014). Does humor predict job satisfaction? a mediational role of self-efficacy. Pakistan Journal of Social and Clinical Psychology, 12-16.

Daryansyah, H., \& Duryati. (2015). Hubungan persepsi terhadap sense of humor pimpinan dan kepuasan kerja karyawan PT. X. Jurnal RAP UNP, 146-156.

Fritz, H., Leslie, N., \& Melissa, M. (2017). Humor use moderates the relation of stressful life events with psychological distress. Personality and Social Psychology Bulletin, 845 859.

Griffin, R. W., \& Gregory, M. (2013). Organizational behavior: managing 
people and organizations (11th ed.). USA: Cengage Learning.

Jhonson, S., Cooper, C., Cartwright, S., Donald, I., Taylor, P., \& Millet, C. (2005). The experience of workrelated stress across occupational. Journal of Managerial Psychology, 178187.

Lady, L., W. S., \& A. M. (2019). Analisis tingkat stres kerja dan faktor-faktor penyebab stres kerja pada pegawai BPBD Kota Cilegon. Journal Industrial Services, 191-197.

Magnus, J., David J, G., \& Chockalingam, V. (2012). A meta-analysis of positive humor in the workplace. Journal of Managerial Psychology, 155190.

Maryam, S. (2017). Strategi coping: teori dan sumberdayanya. Jurnal Konseling, 101-107.

Morreall, J. (1991). Humor and work. Walter de Gruyter, 359-373.

Munandar, M., Endang Siti, A., \& M Soe'oed, H. (2014). Pengaruh keselamatan, kesehatan kerja (K3) dan insentif terhadap motivasi dan kinerja karyawan. Jurnal Administrasi Bisnis, 1-9.

Quick, J. C., M, M.-F., \& D, L. N. (2017). Job stress. Refrence module in neuroscience and behavioral Psychology, $1-8$.

Romero, E., \& Kevin , W. (2006). The use of humor in the workplace. Academy of Management Perspectives, 58-69.

Satria, D. G. (2020). Hubungan antara sense of humor dengan kemampuan interpersonal karyawan PT. Unicam Indonesia.
Skripsi, Universitas Negeri Yogyakarta.

Sormin, T. (2016). Faktor yang berhubungan dengan stres kerja pada pekerja pabrik pengolahan kelapa sawit. Jurnal Keperawatan, 4651.

Sugiyono. (2017). Metode penelitian kuantitatif, kualitatif, dan R\&D. Bandung: Alfabeta.

Sukoco, I., \& M. R. (2017). The analysis of stress management in press companies: Study of PJTV. Jurnal AdBispreneur, 263-278.

Suyasa, P. T. (2010). Identifikasi jenis humor: lucu, lucu, lucu. ResearchGate, 1-15.

Tambun, P. R. (2018). Hubungan kecerdasan emosi dengan stres kerja pada karyawati PT. PLN UPT Pematangsiantar. Skripsi, Universitas Sumatra Utara.

Wartono, T., \& Supriyadi, M. (2015). Stres dan kinerja di lingkungan kerja yang semakin kompetitif. Jurnal Ilmiah Prodi Manajemen, 153-171.

Widyowati, A., \& E. P. (2016). Hubungan antara kepekaan humor dengan stres kerja pada pegawai Balai Karantina Pertanian Kelas I Semarang Jawa Tengah. Psikologika, 47-56. 